\title{
The Earliest History of Life: Solution to Darwin's Dilemma
}

\author{
J.W. Schopf*
}

* Department of Earth and Space Sciences, Center for the Study of Evolution and the Origin of Life, and Molecular Biology Institute, University of California, Los Angeles, CA 90095

In 1859, Darwin stated the problem: "If the theory [of evolution] be true, it is indisputable that before the lowest Cambrian stratum was deposited ... the world swarmed with living creatures. [Yet] why we do not find rich fossiliferous deposits belonging to these earliest periods ... I can give no satisfactory answer. The case at present must remain inexplicable; and may be truly urged as a valid argument against the views here entertained" [1]. For more than a century, this "missing" record of Precambrian life stood out as one of the greatest unsolved problems in natural science.

In the 1950s, beginning with the work of B.V. Timofeev (1916-1982), in the Soviet Union, and S.A. Tyler (1906-1963) and E.S. Barghoorn (1915-1984), in the United States, progress began. Breakthrough publications appeared in 1965: Barghoorn and Tyler described microbial fossils from Canada's 1,900-million-year-old Gunflint chert; P.E. Cloud (1912-1991) confirmed this find; and Barghoorn and J.W. Schopf reported diverse Precambrian ( $\sim 800$-million-year-old) fossil microbes from the Bitter Springs Formation of central Australia. In the years since, more than a thousand microbial species have been reported from hundreds of Precambrian deposits, and the history of life has been extended to $\sim 3,500$ million years ago, some seven times earlier than was previously known [2]. What was "inexplicable" to Darwin is no longer so to science.

In the present decade, research into the paleobiology of the Precambrian Earth has expanded at an ever-quickening pace. Not only are the great majority of scientists who have focused on Precambrian life living and working today, but the field itself is more active, innovative, rigorous and insightful than ever before. Among the many advances that have stimulated the field, three stand out:

(1) spectacular new finds of ancient microscopic fossils, including latest Precambrian-age animal embryos and diverse $\sim 3,000$-million-year-old microbes, coupled with recent detailed studies of stromatolites, cellular fossils, and fossilized carbonaceous matter evidencing life's existence at $\sim 3,500$ million years ago [3];

(2) important progress toward the use of microfossils for the biostratigraphic zonation of Proterozoic, especially Ediacaran, Precambrian strata [3]; and

(3) the emergence of astrobiology as a vibrant new field of science, a development that has attracted many new workers to Precambrian studies in their search for a plausible analogue for life on other planets.

This renaissance in the study of Precambrian life has been spurred by the introduction of advanced analytical techniques. Among many new techniques, pioneered by numerous workers, two have proven particularly useful: confocal laser scanning microscopy (CLSM) [4] and 2-D [5, 6] and 3-D [7] Raman imagery. Unlike other techniques, CLSM and Raman imagery are non-destructive and non-intrusive, and are not limited to analyses of surface-exposed specimens. Together, they can address the two prime problems that have hindered progress in this science: (1) accurate documentation of the three-dimensional morphology and cellular anatomy of fossilized microbes; 
and (2) establishment of the chemical composition (molecular structure) of the carbonaceous material of which such fossils are composed and that of their enclosing matrices. The data they provide can be used to elucidate the preservational history of the fossils studied [8] and to distinguish between authentic fossils and nonbiologic "look-alikes," [9, 10], a problem that has plagued studies of ancient, Precambrian, microfossils since their inception.

The two techniques are complementary, CLSM detecting the laser-induced fluorescence of the polycyclic aromatic hydrocarbons that are predominant in the carbonaceous material of organicwalled fossils and Raman documenting its molecular structure and identifying associated minerals. Both provide submicron spatial resolution, for CLSM $\leq 200 \mathrm{~nm}$ and for Raman, $\leq 900 \mathrm{~nm}$. Both the usefulness and limitations of the techniques have recently been discussed [11]. Because CLSM is the more rapid of the techniques, we routinely use it as an initial "filter" to determine which of various fossil specimens are most promising for subsequent Raman studies.

Use of the two techniques together, a capability especially useful to paleontology, can provide data unavailable by any other means about the organismal morphology, cellular anatomy, chemistry, and taphonomic and preservational history of carbonaceous microscopic and megascopic fossils, regardless of their geologic age or mode of preservation. One example of the use of CLSM and Raman to analyze an ancient fossil microbe is shown in Fig. 1.

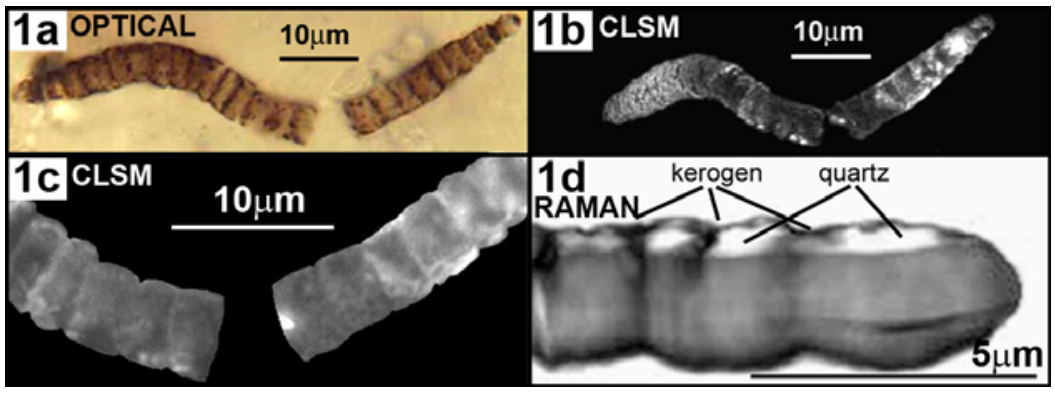

FIG.1. Optical photomicrograph (1a), and CLSM (1b and 1c) and 3-D Raman images (1d) of a cyanobacterium rock-embedded in central Australia's 800-million-year-old Bitter Springs chert.

References

[1] C.R. Darwin, On the Origin of Species by Means of Natural Selection, John Murray, London (1859) Chpt. X.

[2] J.W. Schopf, In: D. Sepkoski and M. Ruse (eds.), The Paleobiological Revolution, Essays on the Growth of Modern Paleontology, Univ. Chicago Press, Chicago (2009) 88.

[3] J.W.Schopf et al., (eds.), Precambrian Res. 173/1-4 (Special Issue) (2009).

[4] J.W. Schopf et al., Astrobiology 6 (2006) 1.

[5] J.W. Schopf et al., Nature 416 (2002) 73.

[6] J.W. Schopf et al., Astrobiology 5 (2005) 333.

[7] J.W. Schopf et al., Geobiology 3 (2005) 1.

[8] J.Y. Chen et al., Proc. Nat. Acad. Sci. USA 104 (2007) 6289.

[9] J.W. Schopf et al., Astrobiology (2008) 735.

[10] J.W. Schopf et al., Precambrian Res. (in press).

[11] J.W. Schopf et al., Precambrian Res. 173 (2009) 39. 